\title{
Immunochemical Studies on Mannans of the Genera Kluyveromyces and Saccharomyces
}

\author{
By J. S̆ANDULA, A. KOCKOVÁ-KRATOCHVÍLOVÁ AND \\ D. ŠIK L \\ Institute of Chemistry of the Slovak Academy of Sciences, \\ Bratislava, Czechoslovakia
}

(Received I6 January 1974; revised I3 March 1974)

\begin{abstract}
SUM MARY
Mannans isolated from Kluyveromyces species, from their imperfect forms Candida pseudotropicalis and Torulopsis sphaerica, and from Saccharomyces species were examined for their reactivities with Kluyveromyces fragilis and Saccharomyces cerevisiae antisera. It was found that Kluyveromyces fragilis, $K$. marxianus, $K$. lactis, Candida pseudotropicalis and Saccharomyces chevalieri possessed a specific antigenic mannan which after acetolysis yielded fragments up to pentasaccharide. Moreover these mannans showed high cross-reactivity with $S$. cerevisiae antiserum that could have been caused by the presence of a determinant group common to Kluyveromyces and Saccharomyces species. Polysaccharides obtained from $K$. polysporus and $K$. drosophilarum showed different immunological properties from the former mannans.
\end{abstract}

\section{INTRODUCTION}

The genus Kluyveromyces was established by van der Walt (1956) for a newly discovered multispored species. The classification by Lodder (I970) altered the definition of the genus to include all of the species formerly classified as Fabospora, Zygofabospora, Dekkeromyces, Guilliermondiella and Kluyveromyces and also some Saccharomyces species. Thus the genus is relatively heterogeneous and the species could be divided into several groups on the basis of various criteria such as number and shape of the ascospores, size and shape of the cells, assimilatory and fermentative properties (Lodder, 1970), DNA composition (Nakase \& Komagata, I97I; Martini, Phaff \& Douglass, 1972; Poncet \& Fiol, 1972), and proton magnetic-resonance (p.m.r.) spectra (Spencer \& Gorin, 1969). Recently Campbell (I972) showed by numerical taxonomy and serological investigation that the genera Kluyveromyces and Saccharomyces are closely related and proposed that they be regarded as a single genus Saccharomyces.

Extensive structural and immunochemical studies have been carried out on cell-wall mannans which form the principal antigen of various yeasts (Summers, Grollman \& Hasenclever, 1964; Suzuki, Sunayama \& Saito, I968; Ballou, 1970). Recently it has been shown that distinct taxonomic groups within the genus Saccharomyces possess mannans differing from each other in structural and immunochemical properties (Šandula, Šikl \& Bauer, 1973; Šandula \& Vojtková-Lepšíková, 1974).

This report presents an immunochemical investigation on mannans isolated from some Kluyveromyces species and their imperfect forms, and compares them with mannans of Saccharomyces species. 


\section{METHODS}

Strains. Cultures of the following organisms were obtained from the Czechoslovak Collection of Yeast and Yeast-like Organisms: Kluyveromyces fragilis CCY $5 \mathrm{I}-\mathrm{I}-\mathrm{I}$, K. marxianus CCY2I-40-I, $K$. lactis CCY2I-3-I, $K$. veronae CCY2I-34-I, $K$. drosophilarum CCY13-4-I, K. polysporus CCY43-I-I, Candida pseudotropicalis CCY29-8-4, Torulopsis sphaerica CCY26I2-4, Saccharomyces cerevisiae CCY2I-4-I3, S. italicus CCY2I-33-1 and S. chevalieri CCY2I-IT-3. Morphological, physiological and biological tests were described in detail by Kocková-Kratochvílová et al. (I969).

Isolation of mannan. Each organism was grown in a semisynthetic liquid medium of the

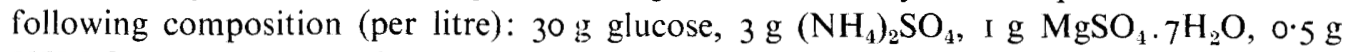
$\mathrm{KH}_{2} \mathrm{PO}_{4}$, I $\mathrm{g}$ yeast autolysate (from Imuna n.p., Michalany, Czechoslovakia) and I $\mathrm{ml}$ of a micro-element mixture in solution (Weinfurtner, Eschenbecher \& Borges, 1959). Cultivation was carried out for 4 days at $28{ }^{\circ} \mathrm{C}$ and the yeasts were harvested by continuous flow centrifugation. The mannans were extracted from the cell paste with $0.2 \mathrm{M}$-sodium chloride solution in an autoclave at $140^{\circ} \mathrm{C}$ (Šikl, Masler \& Bauer, 1969) and purified via the insoluble copper complex formed with Fehling solution.

Acetolysis of mannan. Acetylation and acetolysis of the mannan was performed according to Kocourek \& Ballou (I969). Oligosaccharides were separated on a Sephadex G-25 column $(\mathrm{I} \cdot 6 \times 200 \mathrm{~cm})$. The column was eluted with water at a rate of $\mathrm{I} 2 \mathrm{ml} / \mathrm{h}$ and $2 \mathrm{ml}$ fractions were collected.

General procedures. Total carbohydrate was measured by the phenol-sulphuric acid method (Dubois et al. 1956). Protein was estimated according to Lowry, Rosebrough, Farr $\&$ Randall (I95I). The mannans were hydrolysed in $\mathrm{I} \mathrm{N}-\mathrm{HCl}$ in a sealed tube for $6 \mathrm{~h}$ at $100{ }^{\circ} \mathrm{C}$ and hydrochloric acid was removed by azeotropic distillation with water at room temperature. Descending paper chromatography of the hydrolysates was done on Whatman No. $\mathrm{I}$ in the following system: acetone- $n$-butanol-water $(7: 2: 1$, by vol.) for $24 \mathrm{~h}$. Sugars were detected on paper chromatograms with diphenylamine-aniline-phosphoric acid reagent ( $10 \mathrm{ml}$ of $\mathrm{I} \%$ diphenylamine and aniline in acetone and $\mathrm{I} \mathrm{ml}$ of $85 \%$ phosphoric acid).

Immunization of rabbits. Chinchilla rabbits weighing $2 \cdot 0$ to $2.5 \mathrm{~kg}$ were injected intravenously with I to $2 \mathrm{ml}$ of heat-killed yeast suspension ( $5 \mathrm{mg}$ wet cells $/ \mathrm{ml}$ ) twice weekly for 4 to 6 weeks. Seven days after the final injection the rabbits were bled and the serum from three rabbits was pooled and stored at $-20{ }^{\circ} \mathrm{C}$ until used.

Quantitative precipitin reactions. An appropriate amount of mannan dissolved in $0.5 \mathrm{ml}$ buffered saline was added to $0.5 \mathrm{ml}$ antiserum. The mixture was incubated for $2 \mathrm{~h}$ at $37^{\circ} \mathrm{C}$ and thereafter kept for 5 days at $4{ }^{\circ} \mathrm{C}$. The precipitates were collected by centrifugation at $4{ }^{\circ} \mathrm{C}$, twice washed with cold saline, and dissolved in $\mathrm{I} \mathrm{ml} \cdot \mathrm{I} \mathrm{N}-\mathrm{NaOH}$ and their extinction measured at $280 \mathrm{~nm}$.

Immunodiffusion. Double diffusion in agar gel was performed using $\mathrm{x} \cdot 0 \%$ Noble agar (Difco) in buffered saline (phosphate buffer, $\mathrm{pH} 7 \cdot 4$ ). A $0.05 \%$ concentration of the mannan antigen (in some cases $0.2 \%$ ) was placed in the outer wells of the diffusion agar and undiluted antiserum was placed in the central well.

\section{RESULTS}

Forty-three strains, representing the genus Kluyveromyces and the imperfect forms Candida pseudotropicalis and Torulopsis sphaerica, were tested for morphological, physiological, biochemical and serological properties (Kocková-Kratochvílová, Blagodatskaja \& 


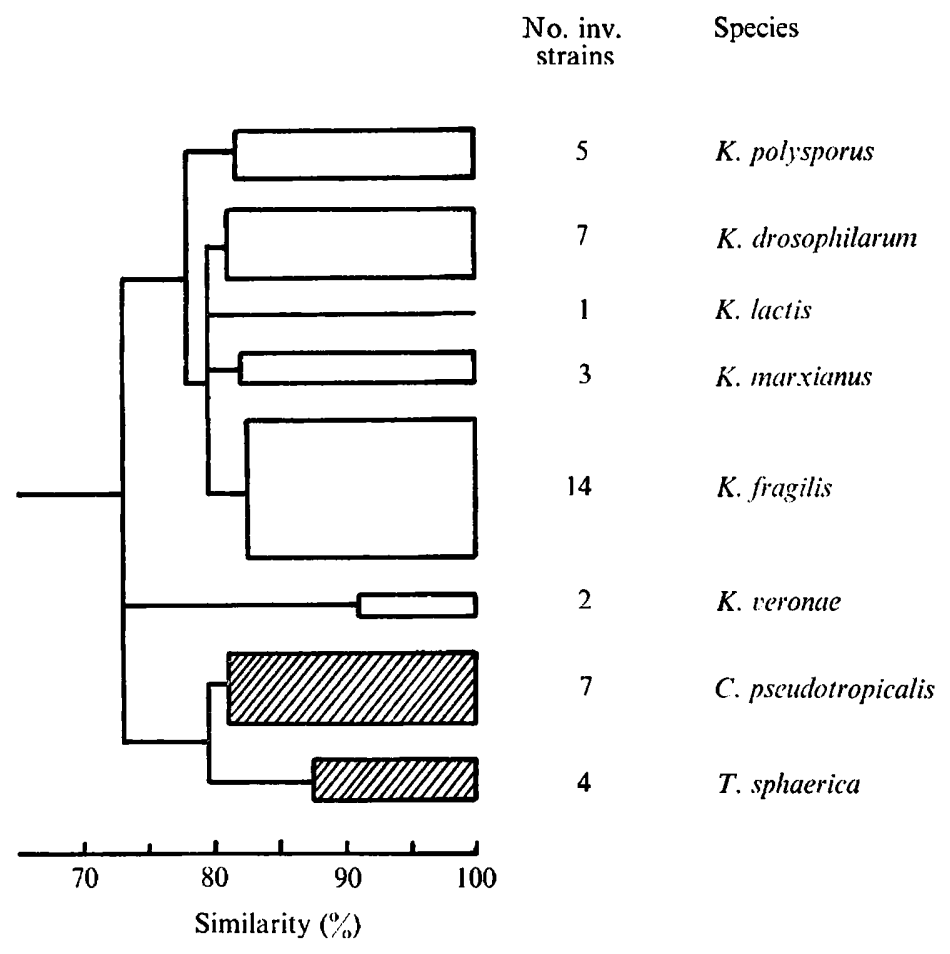

Fig. I. Dendrogram of proposed groups of the genus Kluyveromyces and its imperfect forms Candida pseudotropicalis and Torulopsis sphaerica.

Hronská, 1972). At the $80 \%$ similarity level eight distinct clusters were found (Fig. 1). One strain of each cluster was chosen as representative and from each strain a mannan-containing polysaccharide was isolated via its insoluble copper complex and analysed immunochemically with antisera prepared against $K$. fragilis and $S$. cerevisiae.

The quantitative precipitin reactions of mannans with anti-Kluyveromyces fragilis serum are given in Fig. 2. The mannans of $K$. marxianus and $K$. lactis were the most reactive. Mannan of $C$. pseudotropicalis precipitated almost the same amount of the antibody as did the homologous mannan, whereas mannans of $K$. drosophilarum and $K$. polysporus showed a very low cross-reactivity with $K$. fragilis serum. $K$. veronae mannan precipitated more than $60 \%$ of the antibody, but several times as much mannan was required to reach the point of equivalence than in the homologous reaction.

To investigate the antigenic relationship between the genera Kluyveromyces and Saccharomyces, mannans of various Saccharomyces species were tested with $K$. fragilis antiserum (Fig. 3). Only mannan of $S$. chevalieri was highly cross-reactive with this serum. $S$. cerevisiae and $S$. italicus mannans precipitated approximately $40 \%$ of the antibody compared with the homologous reaction. The mannans of other species belonging to the group of Saccharomyces (sensu stricto) species, e.g. S. bayanus and $S$. uvarum, gave similar precipitin curves to those of $S$. cerevisiae. The precipitating activity of $S$. fermentati mannan, representing the Torulaspora species, was very low. On the other hand the mannans of $K$. fragilis, $K$. lactis, $K$. marxianus and $C$. pseudotropicalis showed high cross-reactivity with $S$. cerevisiae serum, precipitating almost the same amount of antibody as did the homologous mannan.

Absorption of $K$. fragilis serum with Saccharomyces cerevisiae mannan removed a part 


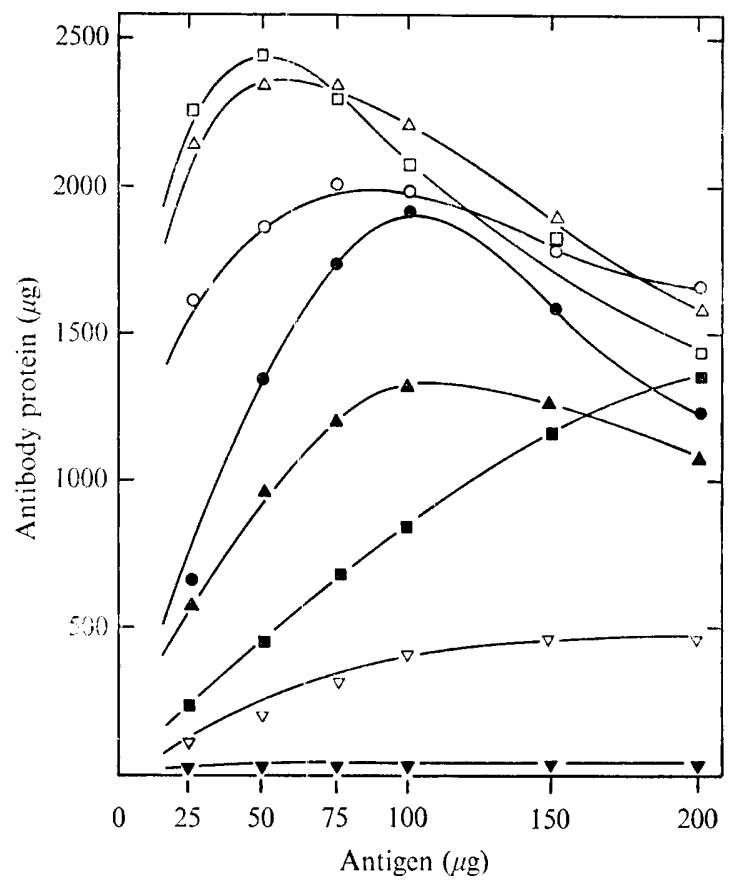

Fig. 2. Precipitin curves of anti-Kluyveromyces fragilis 5I-I-I serum with various mannans: $\square, K$. marxianus; $\triangle, K$. lactis; $\mathrm{O}, K$. fragilis; $\mathbf{O}$, Candida pseudotropicalis; $\mathbf{\Delta}$, Torulopsis sphaerica; $\mathbf{\mathbf { v }}, K$. veronae; $\vee$, K. drosophilarum; $\mathbf{\nabla}, K$. polysporus.

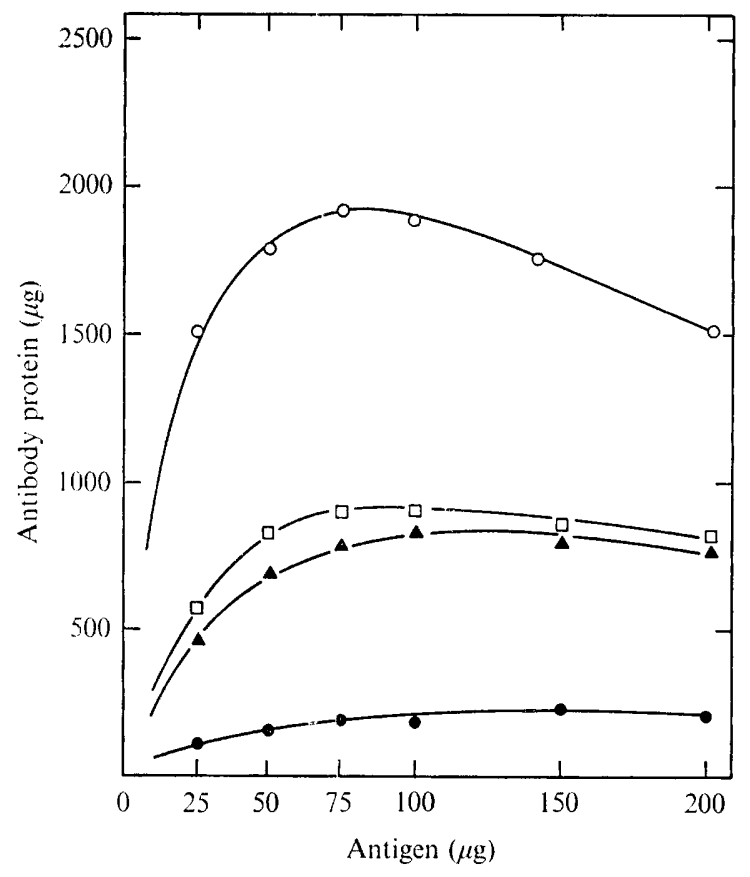

Fig. 3. Precipitin curves showing the cross-reaction of anti-Kluyveromyces fragilis 51-I-I serum with Saccharomyces mannans: $\bigcirc$, Saccharomyces chevalieri; $\square$, S. italicus; $\mathbf{\Delta}$, S. cerevisiae; - S. fermentati. 


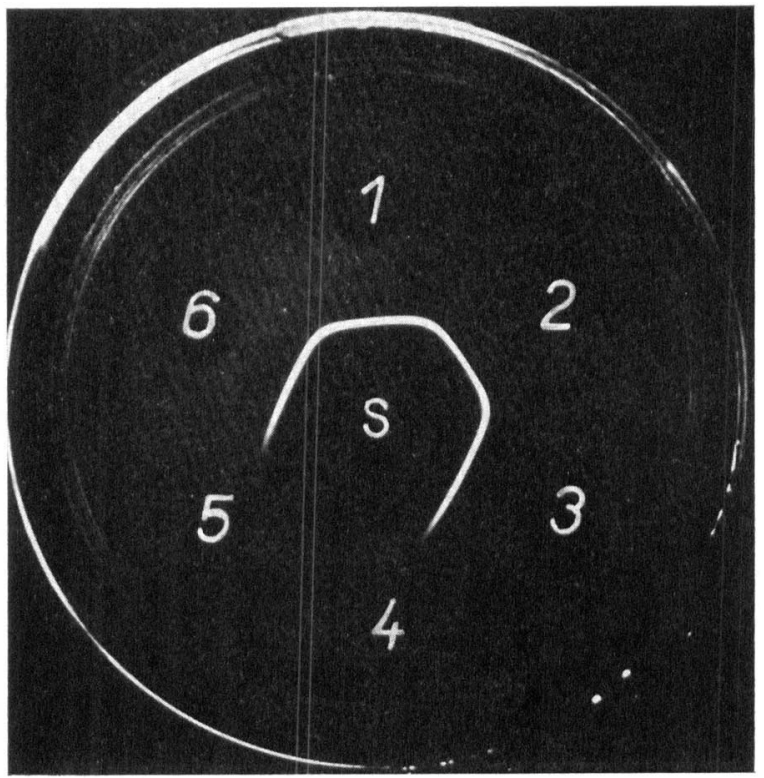

Fig. 4. Agar-gel diffusion pattern of anti-Kluyveromyces fragilis 5I-I-I serum and mannans. Peripheral wells contain mannans: I, K. fragilis; $2, K$.lactis; $3, K$. marxianus; $4, K$. drosophilarum; 5, K. polysporus; 6 , Candida pseudotropicalis. Centre well $\mathrm{S}$ contains $K$. fragilis $5 \mathrm{I}-\mathrm{I}-\mathrm{I}$ antiserum.

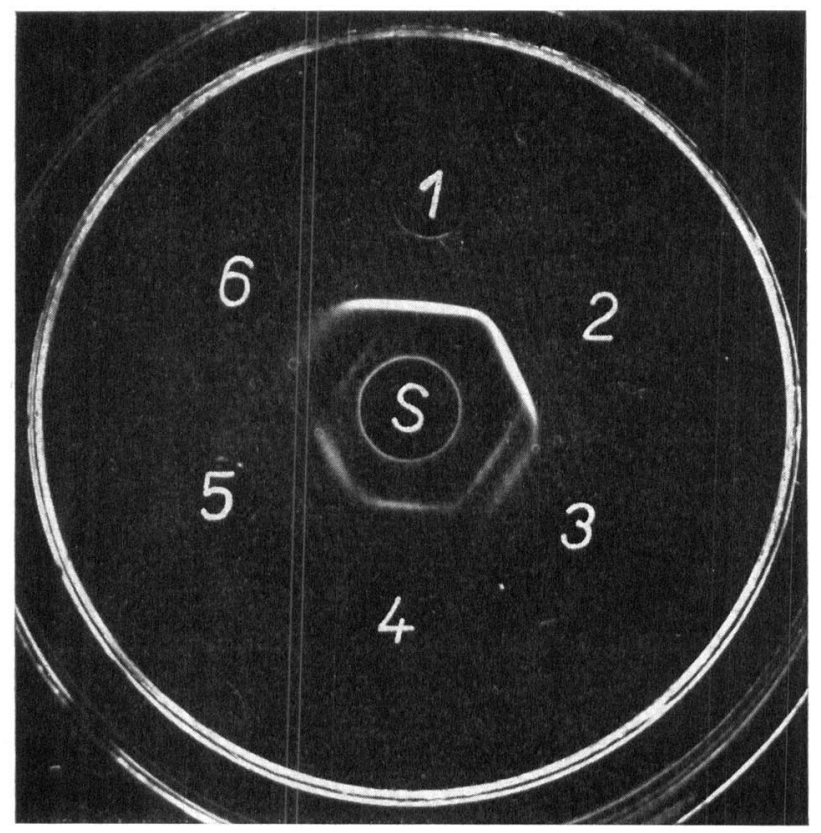

Fig. 5. Agar-gel diffusion pattern of anti-Kluyveromyces fragilis 5I-I-I serum and mannans. Peripheral wells contain mannans: 1 , K. fragilis; 2 , Saccharomyces chevalieri; $3, K$. veronae $(2 \mathrm{mg} / \mathrm{ml})$; 4, S. cerevisiae; $5, S$. italicus; 6, Torulopsis sphaerica $(2 \mathrm{mg} / \mathrm{ml})$. Centre well contains $K$. fragilis 51-1-1 antiserum. 


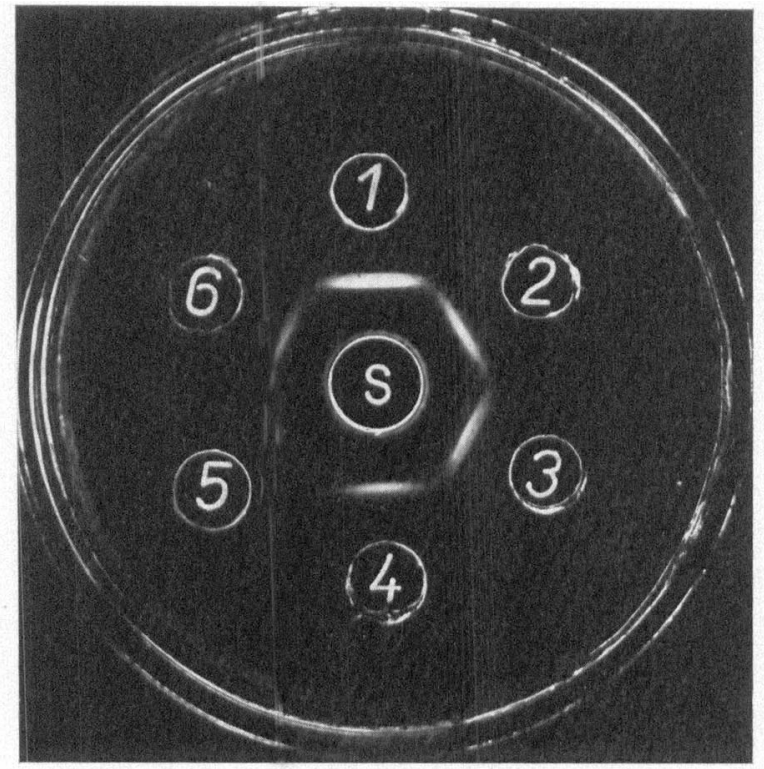

Fig. 6. Agar-gel diffusion pattern of anti-Saccharomyces cerevisiae 2 I-4-13 serum and mannans. Peripheral wells contain mannans: I, S. cerevisiae; 2, Kluyveromyces lactis; 3, K. marxianus; 4, K. fragilis; 5 , K. drosophilarum; 6, Candida pseudotropicalis. Centre well S contains $S$. cerevisiae 2 I-4- 13 antiserum.

of the antibodies corresponding to $S$. cerevisiae determinant, the serum then becoming specific for mannans of $K$. fragilis and related species.

Immunodiffusion results in Fig. 4 present further evidence for antigenic similarities of $K$. fragilis, K. lactis, K. marxianus and C.pseudotropicalis mannans, which formed a sharp, completely fused precipitin line with $K$. fragilis antiserum. Mannans of $K$. drosophilarum and $K$. polysporus failed to give any precipitin bands.

Mannan from $S$. chevalieri showed complete fusion with the line formed by mannan of $K$. fragilis. Mannans of $S$. cerevisiae. S. italicus and other Saccharomyces (sensu stricto) species also formed one precipitin line but not identical with that of the mannan of $K$. fragilis and related mannans. Mannans of $K$. veronae and Torulopsis sphaerica at higher concentration $(0.2 \%)$ formed only two faint lines, one of them being identical with the specific antigen of Kluyveromyces species, whereas the second showed a partial fusion and spur formation with the line formed by S. cerevisiae and S. italicus antigens (Fig. 5). Figure 6 shows immunodiffusion patterns of mannans tested with $S$. cerevisiae antiserum.

To investigate the length of the side chains the backbone of the mannans was specifically split by the controlled acetolysis method (Kocourek \& Ballou, 1969) and the fragments separated by column chromatography on Sephadex G-25. All mannans giving high crossreactivity with Kluyveromyces fragilis antiserum showed five peaks corresponding to those of mannose, mannobiose and oligosaccharides up to mannopentaose, whereas mannans of Saccharomyces (sensu stricto) species yielded acetolysates only up to mannotetraose (Šandula \& Vojtková-Lepšíková, 1974). Acetolysis patterns for K. fragilis, K. marxianus and S. chevalieri are given in Fig. 7.

Antiserum to $K$. fragilis agglutinated very weakly the whole cells of Kluyveromyces species which possessed homologous polysaccharide antigen, although their mannans reacted very strongly in precipitin reactions. 


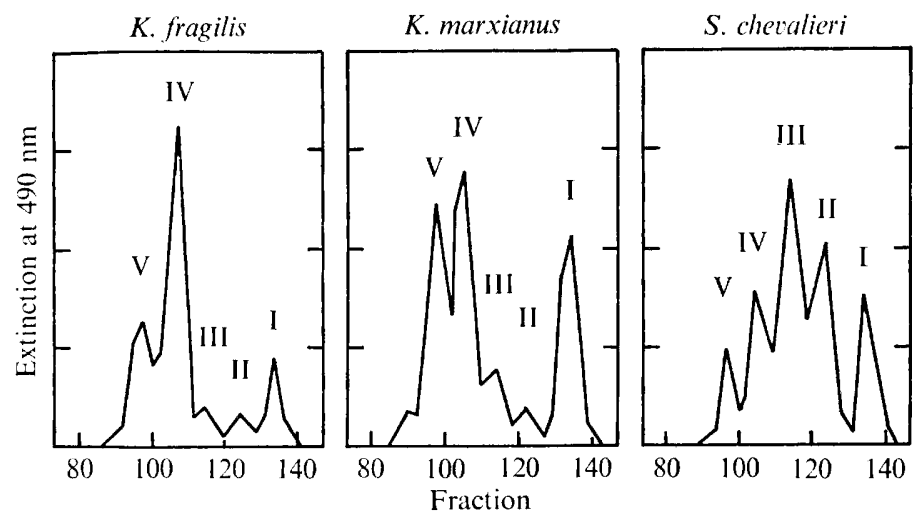

Fig. 7. Sephadex G-25 gel filtration patterns of the oligosaccharides obtained by controlled acetolysis of the mannans from $K$. fragilis, $K$. marxianus and $S$. chevalieri. Peak $I$, monosaccharide; II, disaccharide; III, trisaccharide; IV, tetrasaccharide; V, pentasaccharide.

\section{DISCUSSION}

Kluyveromyces fragilis, $K$. marxianus and $K$. lactis possess a specific polysaccharide antigen differing from the antigens of the other yeast species, as proved by immunochemical analysis of their mannans presented here.

In a recent study, Raschke \& Ballou (1972) demonstrated that Kluyveromyces lactis mannan contains two immunodominant groups. One is a mannotetraose side chain which is also present in the $S$. cerevisiae mannan and the other a pentasaccharide formed by a mannotetraose unit substituted with $N$-acetyl-D-glucosamine, and specific for this species.

The occurrence of tetra- and pentasaccharide fragments after controlled acetolysis of $K$. fragilis and $K$. marxianus mannans, and their immunochemical identity with $K$. lactis mannan, suggest that mannans of these micro-organisms possess identical immunodeterminant groups.

During immunization of two rabbits with intact cells of $K$. fragilis, antibodies with two different specificities were formed, part of the activity being specific for related Kluyveromyces species while the other part, which represents about $40 \%$ of all precipitable antibody, caused cross-reactivity with Saccharomyces species. The fact that these mannans form only one precipitin line in immunodiffusion tests suggests that both determinants were part of the same polysaccharide molecule.

It was found that the mannotetraose side chain was the main antigenic determinant in S. cerevisiae (Ballou, 1970) and in other Saccharomyces (sensu stricto) species (Šandula \& Vojtková-Lepšíková, 1974). High cross-reactivity of Kluyveromyces mannans with anti$S$. cerevisiae serum showed that the above mentioned determinant should be present also in Kluyveromyces mannans.

Kluyveromyces veronae shows low taxonomical similarity with the other species of the genus Kluyveromyces, being related only at $73 \%$ matching. Our results, based on immunochemical studies of wall polysaccharides, show antigenic relationship of $K$. veronae to $K$. fragilis and related species as well as to Saccharomyces (sensu stricto) species. The weaker reactivity of $K$. veronae mannan with $K$. fragilis antiserum than with the other Kluyveromyces mannans could be caused by the lower concentration of determinant groups in $K$. veronae mannan.

We have found that only $S$. chevalieri possessed mannan identical with specific Kluy- 
veromyces antigen. Spencer \& Gorin (1969) on the basis of similarity of p.m.r. spectra classified mannans of $K$. fragilis, $K$. marxianus and $S$. chevalieri into one group. Comparison of these species showed $80.4 \%$ matching coefficients.

Campbell's (1972) serological classification of the genera Saccharomyces and Kluyveromyces agrees well with the results presented here except for $K$. lactis. He placed $K$. fragilis, $K$. marxianus and $S$. chevalieri into the 'B' serological group, while $K$. lactis was placed in the 'C' group with $S$. cerevisiae. Likewise Spencer \& Gorin (1969) reported that according to the p.m.r. spectra, K. lactis mannan differs from that of the previous group. On the other hand, according to Raschke \& Ballou (1972), K. lactis mannan possesses the same determinant groups as mannan of $K$. marxianus. These discrepancies could be the result of the use of antigenically different strains of the same species.

It is apparent that in culture collections there exist various strains of $K$. lactis with different origins. The original type cultures described by Dombrowski in 19I0 (Guilliermond, 1912) were three: Zygosaccharomyces lactis $\alpha$, Saccharomyces lactis $\alpha$ and Saccharomyces lactis $\beta$, all being different in their phenotype. Dombrowski considered the last strain to be very similar to $S$. fragilis. Therefore strains used by different authors cannot be compared while their origins remain unknown.

Candida pseudotropicalis was classified by Lodder (1970) as the imperfect form of $K$. fragilis. We have found that the mannan of $C$. pseudotropicalis is antigenically very similar to mannan of $K$. fragilis. On the other hand $T$. sphaerica, the imperfect form of $K$. lactis, possesses a mannan which shows a relatively low cross-reactivity with $K$. fragilis antiserum. This observation is supported by Spencer \& Gorin (1969), who also found differences in the p.m.r. spectra of the latter two mannans.

\section{REFERENCES}

Ballou, E. C. (1970). A study of the immunochemistry of three yeast mannans. Journal of Biological Chemistry 245, I197-I203.

CAmpbeLl, I. (1972). Numerical analysis of the genera Saccharomyces and Kluyveromyces. Journal of General Microbiology 73, 279-30I.

Dubois, M., Gilles, K. A., Hamilton, J. J., Rebers, P. A. \& Smith, F. (1956). Colorimetric method for determination of sugars and related substances. Analytical Chemistry 28, 350-356.

Guilliermond, A. (1912). Les levures, pp. 316, 384, 385. Edited O. Doint and Son. Paris.

Kocková-Kratochvílová, A., Blagodatskaja, V. \& Hronská, L. (I972). The grouping of the species within the genus Kluyveromyces van der Walt. In Yeasts, Models in Science and Technics, pp. 339--353. Bratislava: Slovak Academy of Sciences.

Kocková-Kratochvíloví, A., Šandula, J., Sedelárová, L., Vojtková-Lepšíková, A. \& Kasmanová, M. (1969). Taxonometric Studies of the Genus Saccharomyces (Meyen) Rees. Biologické práce XV/I, I. Bratislava: Slovak Academy of Sciences.

KoCoureK, J. \& BAlLoU, C. E. (I969). Method for fingerprinting yeast cell wall mannans. Journal of Bacteriology IOo, I175-118I.

LodDer, J. (1970). The Yeasts, a Taxonometric Study, 2nd edn. Amsterdam: North-Holland Publishing.

Lowry, O. H., Rosebrough, N. J., Farr, A. L. \& Randall, R. J. (1951). Protein measurement with the Folin phenol reagent. Journal of Biological Chemistry 193, 265-275.

Martini, A., Phaff, H. J. \& Douglass, S. A. (1972). Deoxyribonucleic acid base composition of species in the yeast emend. Van der Walt. Journai of Bacteriology III, 48I-487.

Nakase, T. \& Komagata, K. (1971). Significance of DNA base composition in the classification of the yeast genus Saccharomyces. Journal of General and Applied Microbiology 17, 227-238.

PONCET, S. \& FIOL, J. B. (1972). Taxonomy of Kluyveromyces: evaluation of DNA base composition. Antonie van Leeuwenhoek 38, 145-152.

RASChKE, W. C. \& Ballou, C. E. (1972). Characterization of a yeast mannan containing $N$-acetyl-D-glucosamine as an immunochemical determinant. Biochemistry II, 3807-3816. 
S̆ANDUl.A, J., ŠIKL, D. \& BAUER, S̆. (1973). Immunochemical studies on mannans of the genus Saccharomyces. Group of Torulaspora species. Folia microbiologica (Praha) $\mathbf{1 8}, 467-473$.

ŠAndula, J. \& VoJTKovÁ-LepšíkovÁ, A. (1974). Immunochemical studies on mannans of the genus Saccharomyces. Group of Saccharomyces sensu stricto species. Folia microbiologica (Praha) 19, 94-10r.

Šikl, D., Masler, L. \& Bauer, Š. ( I969). Polysaccharides of Torulopsis colliculosa (Hartman) Saccardo. Isolation and structural features of extracellular mannan and cell-wall mannan. Collection of Czechoslovak Chemical Communications 35, 2965-2972.

Spencer, J. F. T. \& Gorin, P. A. J. (1969). Systematics of the genera Saccharomyces, Schizosaccharomyces, Endomycopsis, Kluyveromyces, Schwanniomyces and Brettanomyces: proton magnetic resonance spectra of the mannans and mannose-containing polysaccharides as an aid in classification. Antonie van Leeuwenhoek 35, 36I-378.

Summers, D., Grollman, A. P. \& Hasenclever, H. F. (1964). Polysaccharide antigens of Candida cell wall. Journal of Immunology 92, 491-499.

Suzuki, S., Sunayama, H. \& Saito, T. (1968). Studies on the antigenic activity of yeasts. I. Analysis of the determinant groups of the mannan of Saccharomyces cerevisiae. Japan Journal of Microbiology 12, 19-24.

VAN DER WALT, J. P. (1956). Kluyveromyces - a new yeast genus of the Endomycetales. Antonie van Leeunenhoek 22, 265-272.

Weinfurtner, F., Eschenbecher, F. \& Borges, W. D. (1959). Zum Wuchsstoffbedarf von Saccharomyces carlsbergensis. Zentralblatt fïr Bakteriologie, Parasitenkunde, Infektionskrankheiten und Hygiene (Abteilung II) Ir3, I34. 